\title{
Comparison of circulating dendritic cell and 1 cossmak monocyte subsets at different stages of atherosclerosis: insights from optical coherence tomography
}

\author{
Jianhui Zhuang ${ }^{1 \dagger}$, Yang Han ${ }^{2+}$, Dachun $\mathrm{Xu}^{1 \dagger}$, Guofu Zhu', Shekhar Singh', Luoman Chen ${ }^{1}$, Mengyun Zhu',
} Wei Chen ${ }^{1}$, Yawei $\mathrm{Xu}^{1}$ and Xiankai $\mathrm{Li}^{1,3^{*}}$ (D)

\begin{abstract}
Background: While specific patterns of circulating dendritic cells (DCs) and monocytes are associated with the incidence of coronary artery disease, the characterization of circulating DC and monocyte subsets in patients with different stages of atherosclerosis remains unclear.

Methods: Forty-eight patients with unstable angina pectoris (UAP) diagnosed by angiography were enrolled. Likewise, 31 patients with ST-segment elevation myocardial infarction (STEMI) were enrolled and confirmed with the presence of thrombosis by angiography. Plaque features of 48 UAP patients were evaluated at the culprit lesions by OCT. Circulating myeloid DCs (mDCs), plasmacytoid DCs (pDCs) and monocyte subsets were analyzed using flow cytometry.

Results: The proportions and absolute counts of mDC2s, which specifically express CD141 and possess the ability to activate CD8+ T lymphocytes, significantly decreased in patients with UAP and STEMI when compared with controls $\left(0.08 \times 10^{4} \pm 0.05 \times 104 / \mathrm{ml}\right.$ and $0.08 \times 10^{4} \pm 0.06 \times 104 / \mathrm{ml}$ vs. $\left.0.11 \times 10^{4} \pm 0.06 \times 104 / \mathrm{ml}, p=0.027\right)$. On the other hand, patients with UAP and STEMI had significantly higher proportions and counts of Mon2 subsets. In the OCT subgroup, patients with thin-cap fibroatheroma (TCFA) had higher proportions and absolute number of Mon2 $(11.96 \% \pm 4.27 \%$ vs. $9.42 \% \pm 4.05 \%, p=0.034 ; 5.17 \times 104 / \mathrm{ml} \pm 1.92 \times 104 / \mathrm{ml}$ vs. $3.53 \times 104 / \mathrm{ml} \pm 2.65 \times 104 / \mathrm{ml}$, $p=0.045)$ than those without TCFA. However, there was no remarkable difference in mDC2s between patients with and without TCFA.
\end{abstract}

Conclusions: Circulating Mon2 appears to be a promising marker for the severity of atherosclerotic plaque.

Keywords: Dendritic cells, Monocytes, Plaque vulnerability, Optical coherence tomography

\section{Background}

During the development of coronary atherosclerosis, atherosclerotic plaque enlargement accompanied with narrowing of arterial luminal results in a series of chronic ischemic manifestations. More seriously, plaque instability and ensuing rupture with superimposed thrombi eventually lead to myocardial infarction and

\footnotetext{
* Correspondence: lixiankai@tongji.edu.cn

${ }^{\dagger}$ Equal contributors

'Department of Cardiology, Shanghai Tenth People's Hospital, Tongji University School of Medicine, Shanghai, China

${ }^{3}$ Department of Cardiology, Shigatse People's Hospital, Shigatse, Tibet, China Full list of author information is available at the end of the article
}

sudden death [1]. Thin-cap fibroatheroma (TCFA) is the most common phenotype of vulnerable plaque and is the precursor of plaque rupture. Although a greater understanding of lesion dimensions favors the clinical detection of TCFA in coronary artery disease (CAD) patients, coronary angiography alone could not provide comprehensive information on plaque morphology beyond luminal narrowing. Current clinical studies have suggested that optical coherence tomography (OCT) is one of the most preferred invasive approaches that allow high-resolution $(10 \mu \mathrm{m})$ tomographic intra-arterial imaging [2,3]. 
As professional antigen-presenting cells, monocytes and dendritic cells (DCs) possess the ability to recognize and present antigens to $\mathrm{T}$ cells [4]. Human circulating monocytes could be categorized into three subsets according to different expression of membrane receptors CD14 and CD16: a numerically dominant CD14+ +CD16- subset (Mon1), an intermediate CD14++CD16+ subset (Mon2), and a non-classical CD14 + CD16++ subset (Mon3) [5, 6]. Given the heterogeneity of circulating monocytes, the exact identity of atherosclerosisrelated monocyte subsets deserves careful consideration. In this regard, some studies demonstrated that CD16 positive monocytes were associated with the incidence of myocardial infarction and in-stent restenosis [7, 8]. Furthermore, Rogacev et al. [9] observed that Mon2 subsets independently predicted the incidence of cardiovascular disease. Conversely, an earlier study by Shantsila et al. [10] did not find a marked correlation between monocyte subsets and the incidence of CAD. To our best knowledge, the relationship between monocyte subsets and atherosclerotic progress has not been examined.

Depending on the origin, location and function, DCs comprise two heterogeneous subpopulations. For human, plasmacytoid DCs (pDCs) express the surface marker blood dendritic cell antigen (BDCA)-2, while myeloid DCs (mDCs) could be categorized into $\mathrm{mDC} 1$ subsets with BDCA-1 and mDC2 subsets with BDCA-3 [11]. Recent reviews have helped solidify the knowledge of pDCs and $\mathrm{mDCs}$ in atherosclerosis [12]. Indeed, several clinical trials attempting to address whether circulating DC subsets correlate with the incidence and severity of CAD reached contradictory results $[13,14]$.

Toward this end, we sought to explore which subsets of DCs and monocytes are associated with the emergence, vulnerability and rupture of atherosclerotic plaques identified by coronary angiography and OCT.

\section{Methods}

\section{Study population}

Between April 2013 and July 2014, 112 subjects with acute chest pain as their first clinical manifestation undergoing coronary angiography and showing identifiable de novo culprit lesions in any native coronary artery were admitted at our hospital (Additional file 1: Figure S1). Among these individuals, 48 unstable angina pectoris (UAP) patients undergoing OCT were finally enrolled in the study. UAP was defined as angina at rest, accelerated angina or new-onset angina without elevation of cardiac markers [15]. Thirty-one ST-segment elevation myocardial infarction (STEMI) patients confirmed with the presence of acute thrombosis secondary to plaque rupture by angiography were also enrolled. The diagnosis of STEMI is clearly defined as STelevation in at least two contiguous leads $>0.2 \mathrm{mV}$
( $2 \mathrm{~mm})$ in chest leads and/or $>0.1 \mathrm{mV}(1 \mathrm{~mm})$ in limb leads, and elevation of serum cardiac troponin-T (cTnT) level with at least one value above the 99th percentile upper reference limit [16]. Thirty-three subjects with possible cardiac etiology but free of luminal diameter narrowing $\geq 50 \%$ at coronary angiography served as controls.

The study was approved by Ethics Committee of Shanghai Tenth People's Hospital and all individuals provided written informed concept before participation.

\section{Angiography and optical coherence tomography analysis}

The located vessel, minimum lumen area and percent diameter stenosis of culprit lesion were measured. Culprit lesions were identified from a combination of electrocardiographic changes, echocardiographic findings and angiographic lesion morphologies.

Frequency domain Optical coherence tomography (OCT) imaging (C7XR, St. Jude, USA) was performed before any intervention and after intracoronary administration of nitroglycerin $(0.2 \mathrm{mg})$ in UAP patients with a TIMI flow grade of 3 . OCT images were digitalized and analysed offline according to the principals of OCT imaging described elsewhere [2, 17]. Two independent experienced clinicians who were blinded to the angiographic and clinical data analyzed the OCT images using validated criteria for plaque characterization (Additional file 2: Figure S2). Lipid cores at culprit lesions were defined as diffusely bordered, signal-poor regions. A fibrous cap was identified as a signal-rich homogenous region overlying a lipid core, which was characterized by a diffusely bordered, signal-poor region on the OCT image. Fibrous cap thickness was measured at the thinnest point in culprit plaques for three different times and the average value was calculated. The thinnest fibrous cap thickness was defined as the distance from the arterial lumen to the inner border of the lipid pool where the fibrous cap thickness is considered minimal in non-ruptured lipid-rich plaques. TCFA was defined as a plaque presenting lipid content for $>90$ degrees, and with thinnest part of the fibrous cap measuring $<65 \mu \mathrm{m}$ [18]. In the current research, there is no case enrolled with TCFA in all 3 vessels at the same time as inner quality control.

\section{Analysis of circulating DCs and monocytes by flow cytometry}

Approximate 3-5 ml peripheral blood samples were taken at the day after admission from control group and UAP patients who had fasted overnight, while blood samples from STEMI patients were collected at the day of charge. It should be noted that all pheripheral blood samples from study population were obtained before coronary angiography. Peripheral 
leukocyte, polymorphonuclear granulocytes (PMNs), lymphocyte and monocyte counts were determined by Coulter Automated Hematology Analyzer (Beckman Coulter, USA). DC subsets from enrollments were analyzed using Blood Dendritic Cell Enumeration Kit (Miltenyi Biotec, Netherlands) [14]. Four-color flow cytometry (FACS Calibur, BD Biosciences, USA) was conducted using monoclonal antibodies against CD14, CD19, BDCA-1, BDCA-2 and BDCA-3 that were directly conjugated with fluorochromes. Dead cells, granulocytes, CD19+ B cells and CD14+ monocytes were excluded. The $\mathrm{mDC} 1 \mathrm{~s}$ were defined as cells positive for BDCA-1, while $\mathrm{mDC} 2 \mathrm{~s}$ were BDCA-3 immunopostive cells and pDCs were BDCA-2 immunopostive cells. To achieve the absolute $\mathrm{mDC} 1, \mathrm{mDC} 2$ and $\mathrm{pDC}$ count $/ \mathrm{ml}$, we set the above determined DCproportions in relation to the total leucocyte count/ $\mathrm{ml}$. Monocyte subsets were analyzed in a whole-blood assay using $100 \mu \mathrm{l}$ of whole blood as previously described [19]. FSC/SSC gate was positioned to exclude cell debris and granulocytes and monocytes were identified and gated in a CD45 (Miltenyi Biotec, Netherlands)/CD86 (BD Biosciences, USA) dot plots. Blood cells were simultaneously stained with antiCD14-FITC (Miltenyi Biotec, Netherlands), antiCD16-PE (Miltenyi Biotec, Netherlands) and antiCCR2-APC (R\&D Systems, UK) antibodies for $15 \mathrm{~min}$ at room temperature and analyzed by flow cytometry (Additional file 3: Figure S3). The flow cytometry for identifying DC and monocyte subsets was performed by one expert technician who was blind to the coronary angiography and OCT results.

\section{Biochemical analysis}

Plasma levels of fasting glucose, total cholesterol and triglyceride, low-density lipoprotein cholesterol (LDL-C), high-density lipoprotein cholesterol (HDL-C) and high sensitivity C-reactive protein (hs-CRP), and serum levels of cTnT and creatine kinase-MB (CK-MB) were measured by colorimetric enzymatic assay systems (Roche MODULAR P-800, Swiss Confederation). Plasma levels of fibrinogen (Diagnostic Stago, France) and MMP9 (R\&D System, USA) were measure using enzyme-linked immunosorbent assay by an automatic microplate reader (SpectraMaxi3, Molecular Devices, USA).

\section{Statistical anaylsis}

Data were reported as mean \pm standard deviation (SD) for continuous variables and as proportions for categorical variables. Student $t$ test was undertaken to examine the differences between two groups. ANOVA test and Bonferroni correction were performed to compare the differences among controls, UAP patients and STEMI patients. The differences between categorical variables were determined using $X$ [2] test. Correlations between circulating DC and monocyte subsets and plaque characteristics were tested using the Pearson's correlation test. A $p$ value of $<0.05$ was considered statistically significant. Calculations were carried out using SPSS 14.0 software (SPSS Inc., USA).

\section{Results \\ Baseline characteristics of patients}

The baseline characteristics of enrollments are summarized in Additional file 4: Table S1. There was a male predominance in UAP and STEMI groups. The prevalence of smoking was higher in UAP and STEMI groups (35.4\% and $51.6 \%$, respectively) than in control group (12.1\%). STEMI patients had higher levels of fasting glucose and triglyceride compared with healthy controls (fasting glucose: $7.4 \pm 3.5 \mathrm{mmol} / \mathrm{L}$ vs. $5.5 \pm 2.1 \mathrm{mmol} / \mathrm{L}$; triglyceride: $3.0 \pm 1.4 \mathrm{mmol} / \mathrm{L}$ vs. $1.7 \pm 1.2 \mathrm{mmol} / \mathrm{L}$ ). By definition, serum levels of cTnT and CK-MB were prominently higher in STEMI group as compared with control and UAP groups. Several established inflammatory markers such as hs-CRP, fibrinogen and MMP were markedly elevated in UAP and STEMI patients.

\section{Comparison of circulating DC and monocyte subsets among control, UAP and STEMI groups}

Compared with controls and UAP patients, percent PMNs and PMNs/lymphocytes ratio were significantly higher, while a relative lower percentage of lymphocytes was observed in STEMI patients (Table 1). Although the percentages of $\mathrm{mDC} 1 \mathrm{~s}, \mathrm{mDC} 2 \mathrm{~s}$ and $\mathrm{pDCs}$ were markedly lower in UAP and STEMI patients, the total numbers of $\mathrm{mDC} 1 \mathrm{~s}, \mathrm{mDCs}$ and $\mathrm{pDCs}$ were comparable among three groups because total leukocyte count was greatly higher in UAP and STEMI patients. In line with percent $\mathrm{mDC} 2 \mathrm{~s}$, the absolute number of $\mathrm{mDC} 2 \mathrm{~s}$ was lower in UAP and STEMI patients when compared with healthy controls $\left(0.08 \times 10^{4} \pm 0.05 \times 104 / \mathrm{ml}\right.$ and $0.08 \times 10^{4} \pm 0.06 \times 104 / \mathrm{ml}$ vs. $0.11 \times 10^{4} \pm 0.06 \times 104 /$ $\mathrm{ml}, p=0.027)$. With regard to monocyte subsets, the percentage of total monocytes, as well as percent Mon1 subsets, was similar among three groups. The percentage of Monocyte 2 (Mon2) subsets was higher in UAP and STEMI patients than that in healthy controls $(10.61 \% \pm 4.17 \%$ and $13.38 \% \pm 3.44 \%$ vs. $7.44 \% \pm 2.40 \%$, $p<0.001)$. In contrast, UAP and STEMI patients had lower percentages of Mon3 subsets as compared with healthy controls $(6.97 \% \pm 3.91 \%$ and $5.62 \% \pm 4.96 \%$ vs. $10.29 \% \pm 6.17 \%, p=0.001)$. While the absolute number of Mon2 was markedly higher in UAP and STEMI patients $(4.33 \times 104 / \mathrm{ml} \pm 2.39 \times 104 / \mathrm{ml}$ vs. $7.22 \times 104 /$ $\mathrm{ml} \pm 3.67 \times 104 / \mathrm{ml}, \mathrm{p}<0.001)$, there was no significant difference in the absolute number of Mon3 among three groups (control, UAP and STEMI group: $4.43 \times 104 /$ 
Table 1 Total counts and proportions of peripheral blood cells in three groups

\begin{tabular}{|c|c|c|c|c|}
\hline & Control $(n=33)$ & $\operatorname{UAP}(n=48)$ & STEMI $(n=31)$ & $p$ value \\
\hline $\mathrm{WBC}, \times 10^{6} / \mathrm{ml}$ & $6.47 \pm 1.72$ & $6.99 \pm 1.97$ & $8.88 \pm 2.41$ & $<0.001$ \\
\hline PMN, \% WBC & $58.10 \pm 8.81$ & $60.74 \pm 9.64$ & $76.51 \pm 10.59$ & $<0.001$ \\
\hline Lym, \% WBC & $32.48 \pm 7.84$ & $32.11 \pm 9.43$ & $16.65 \pm 9.44$ & $<0.001$ \\
\hline PMN/Lym ratio & $1.99 \pm 0.96$ & $2.26 \pm 1.45$ & $7.02 \pm 5.66$ & $<0.001$ \\
\hline Mon, \% WBC & $6.60 \pm 1.17$ & $5.83 \pm 1.33$ & $6.18 \pm 2.50$ & 0.179 \\
\hline $\mathrm{mDC} 1 \mathrm{~s}, \% \mathrm{WBC}$ & $0.29 \pm 0.05$ & $0.22 \pm 0.05$ & $0.19 \pm 0.04$ & $<0.001$ \\
\hline $\mathrm{mDC} 2 \mathrm{~s}, \% \mathrm{WBC}$ & $1.69 \times 10^{-2} \pm 0.73 \times 10^{-2}$ & $1.11 \times 10^{-2} \pm 0.42 \times 10^{-2}$ & $0.81 \times 10^{-2} \pm 0.52 \times 10^{-2}$ & $<0.001$ \\
\hline $\mathrm{mDCs}, \% \mathrm{WBC}$ & $0.31 \pm 0.05$ & $0.23 \pm 0.05$ & $0.20 \pm 0.04$ & $<0.001$ \\
\hline $\mathrm{pDCs}, \%$ WBC & $0.20 \pm 0.05$ & $0.16 \pm 0.03$ & $0.14 \pm 0.02$ & $<0.001$ \\
\hline $\mathrm{mDC} 1 \mathrm{~s}, \times 10^{4} / \mathrm{ml}$ & $1.89 \pm 0.66$ & $1.60 \pm 0.70$ & $1.73 \pm 0.58$ & 0.151 \\
\hline $\mathrm{mDC} 2 \mathrm{~s}, \times 10^{4} / \mathrm{ml}$ & $0.11 \pm 0.06$ & $0.08 \pm 0.05$ & $0.08 \pm 0.06$ & 0.027 \\
\hline $\mathrm{mDCs}, \times 10^{4} / \mathrm{ml}$ & $2.00 \pm 0.69$ & $1.68 \pm 0.73$ & $1.81 \pm 0.62$ & 0.126 \\
\hline $\mathrm{pDCs}, \times 10^{4} / \mathrm{ml}$ & $1.19 \pm 0.43$ & $1.15 \pm 0.37$ & $1.20 \pm 0.35$ & 0.862 \\
\hline Mon1, \% monocytes & $82.37 \pm 6.31$ & $82.36 \pm 5.54$ & $81.03 \pm 5.91$ & 0.564 \\
\hline Mon2, \% monocytes & $7.44 \pm 2.40$ & $10.61 \pm 4.17$ & $13.38 \pm 3.44$ & $<0.001$ \\
\hline Mon3, \% monocytes & $10.29 \pm 6.17$ & $6.97 \pm 3.91$ & $5.62 \pm 4.96$ & 0.001 \\
\hline Mon $1, \times 10^{5} / \mathrm{ml}$ & $3.45 \pm 0.95$ & $3.42 \pm 1.13$ & $4.41 \pm 1.97$ & 0.007 \\
\hline Mon2, $\times 10^{4} / \mathrm{ml}$ & $3.06 \pm 1.13$ & $4.33 \pm 2.39$ & $7.22 \pm 3.67$ & $<0.001$ \\
\hline Mon3, $\times 10^{4} / \mathrm{ml}$ & $4.43 \pm 3.34$ & $3.14 \pm 2.20$ & $3.32 \pm 2.02$ & 0.187 \\
\hline
\end{tabular}

Values are mean \pm SD

Abbreviations: $D C$ dendritic cell, $L y m$ lymphocyte, $m D C$ myeloid dendritic cell, Mon monocyte, $p D C$ plasmacytoid dendritic cell, $P M N s$ polymorphonuclear granulocytes, WBC white blood cell. $P$-values of risk factors with significance are presented as italic form

$\mathrm{ml} \pm 3.34 \times 104 / \mathrm{ml}, 3.14 \times 104 / \mathrm{ml} \pm 2.20 \times 104 / \mathrm{ml}$ and $3.32 \times 104 / \mathrm{ml} \pm 2.02 \times 104 / \mathrm{ml}, p=0.187)$ due to the gradually elevated number of circulating total monocytes.

Because of the significant differences in the history of smoking and the plasma levels of fasting glucose and triglyceride among three groups, we investigated whether circulating DC and monocyte subsets were associated with these established risk factors. There were no discrepancies in the percentage and count of DC and monocyte subsets among subjects with and without histories of smoking (Additional file 5: Table S2). Likewise, the percentage and count of DC and monocyte subsets were not correlated with the plasma levels of fasting glucose and triglyceride (Additional file 6: Table S3).

Considering the roles of DCs and monocytes in inflammation and myocardial infarction, we examined the correlation of circulating DC and monocytes subsets with inflammatory and myocardial necrotic markers. HsCRP was positively associated with the percentage and absolute number of Mon1 (Additional file 7: Table S4). Similarly, plasma levels of MMP9 were significantly associated with the percentage and absolute number of Mon1 and Mon2. Furthermore, Mon1, Mon2 and $\mathrm{mDCs}$, especially $\mathrm{mDC} 2 \mathrm{~s}$, were closely related to serum levels of cTnT and CK-MB, both of which reflected the severity of myocardial infarction.

\section{Angiography and OCT findings}

Of UAP patients, 20 (41.7\%) were diagnosed as TCFA confirmed by OCT. The angiography and OCT data are shown in Table 2. Patients with TCFA had thinner fibrous cap $(48.5 \mu \mathrm{m} \pm 10.9 \mu \mathrm{m}$ vs. $119.6 \mu \mathrm{m} \pm 22.2 \mu \mathrm{m}$, $p<0.001$ ) and larger lipid core (arc of lipid core, $252.0^{\circ} \pm 77.8^{\circ}$ vs. $170.4^{\circ} \pm 67.7^{\circ}, \mathrm{p}<0.001$ ) compared with patients without TCFA. Plaque calcification was detected more frequently in patients with TCFA (45.0\% vs. $17.9 \%, p=0.041)$. No significant difference was found when comparing patients with and without TCFA in reference to the rate of multivessel disease, culprit lesion distribution, minimal lumen area and percentage of diameter stenosis.

\section{Relation of circulating DCs and monocytes with plaque characteristics}

In a subgroup analysis of 48 UAP patients with plaque morphologies determined by OCT, we found that patients with TCFA had higher proportions of Mon2 subsets $(11.96 \% \pm 4.27 \%$ vs. $9.43 \% \pm 5.15 \%, p=0.035)$ and lower proportions of Mon3 subsets $(4.93 \% \pm 3.22 \%$ vs. $8.43 \% \pm 3.75 \%, p=0.001)$ as compared with patients without TCFA (Table 3). In UAP patients with TCFA, the absolute number of Mon2 was significantly higher than those without TCFA $(5.17 \times 104 / \mathrm{ml} \pm 1.92 \times 104 /$ 
Table 2 Angiographic and OCT finding

\begin{tabular}{|c|c|c|c|}
\hline & Patients with TCFA $(n=20)$ & Patients without TCFA $(n=28)$ & $\mathrm{p}$ value \\
\hline Age, yrs & $62.4 \pm 7.7$ & $60.8 \pm 9.4$ & 0.541 \\
\hline Male & $14(70.0)$ & $25(89.3)$ & 0.091 \\
\hline Multivessel disease & $6(30.0)$ & $7(25.0)$ & 0.701 \\
\hline \multicolumn{4}{|l|}{ Culprit vessel } \\
\hline LAD & $10(50.0)$ & $10(35.7)$ & \multirow[t]{3}{*}{0.457} \\
\hline LCX & $6(30.0)$ & $8(28.6)$ & \\
\hline RCA & $4(20.0)$ & $10(35.7)$ & \\
\hline Fibrous cap thickness, $\mu \mathrm{m}$ & $48.5 \pm 10.9$ & $119.6 \pm 22.2$ & $<0.001$ \\
\hline Arc of lipid core, degrees & $252.0 \pm 77.8$ & $170.4 \pm 67.7$ & $<0.001$ \\
\hline Calcium & $9(45.0)$ & $5(17.9)$ & 0.041 \\
\hline $\mathrm{MLA}, \mathrm{mm}^{2}$ & $4.5 \pm 2.5$ & $5.5 \pm 2.7$ & 0.215 \\
\hline Relative stenosis, \% & $56.8 \pm 13.4$ & $48.4 \pm 16.2$ & 0.064 \\
\hline
\end{tabular}

Values are mean \pm SD or $n(\%)$

Abbreviations: $L A D$ left anterior descending coronary artery, $L C X$ left circumflex coronary artery, $M L A$ minimum lumen area, $O C T$ optical coherence tomography, $R C A$ right coronary artery, TCFA thin-cap fibroatheroma. $P$-values of risk factors with significance are presented as italic form

$\mathrm{ml}$ vs. $3.53 \times 104 / \mathrm{ml} \pm 2.65 \times 104 / \mathrm{ml}, p=0.045)$, whereas the counts of Mon3 did not differ between two groups $(2.23 \times 104 / \mathrm{ml} \pm 1.44 \times 104 / \mathrm{ml}$ vs. $3.66 \times 104 /$ $\mathrm{ml} \pm 2.16 \times 104 / \mathrm{ml}, p=0.059$ ). There were no significant differences in the percent PMNs and lymphocytes, PMNs/ lymphocytes ratio, the absolute and percent DC subsets, and the proportion of Mon1 subsets between patients with and without TCFA. The correlation between plaque characteristics determined by OCT and circulating DCs and monocytes is summarized in Additional file 8: Table S5. The percentage of Mon3 was positively correlated with fibrous cap thickness $(r=0.409, p=0.004)$ and inversely correlated with arc of lipid core $(r=-0.353, p=0.014)$. The absolute number of Mon2 was inversely correlated

Table 3 Total counts and proportions of peripheral blood cells in patients with and without TCFA

\begin{tabular}{|c|c|c|c|}
\hline & Patients with TCFA $(n=20)$ & Patients without TCFA $(n=28)$ & $p$ value \\
\hline $\mathrm{WBC}, \times 10^{6} / \mathrm{ml}$ & $6.88 \pm 1.98$ & $7.12 \pm 1.98$ & 0.690 \\
\hline PMN, \% WBC & $59.83 \pm 9.45$ & $61.33 \pm 9.88$ & 0.613 \\
\hline Lym, \% WBC & $32.75 \pm 8.94$ & $31.70 \pm 9.87$ & 0.717 \\
\hline PMN/Lym ratio & $2.22 \pm 1.69$ & $2.29 \pm 1.31$ & 0.883 \\
\hline Mon, \% WBC & $5.83 \pm 1.25$ & $5.82 \pm 1.41$ & 0.989 \\
\hline $\mathrm{mDC} 1 \mathrm{~s}, \% \mathrm{WBC}$ & $0.24 \pm 0.05$ & $0.21 \pm 0.04$ & 0.134 \\
\hline $\mathrm{mDC} 2 \mathrm{~s}, \% \mathrm{WBC}$ & $1.08 \times 10^{-2} \pm 0.39 \times 10^{-2}$ & $1.13 \times 10^{-2} \pm 0.44 \times 10^{-2}$ & 0.664 \\
\hline $\mathrm{mDC}, \% \mathrm{WBC}$ & $0.25 \pm 0.05$ & $0.23 \pm 0.05$ & 0.151 \\
\hline $\mathrm{pDCs}, \% \mathrm{WBC}$ & $0.15 \pm 0.03$ & $0.16 \pm 0.03$ & 0.285 \\
\hline $\mathrm{mDC} 1 \mathrm{~s}, \times 10^{4} / \mathrm{ml}$ & $1.63 \pm 0.61$ & $1.57 \pm 0.76$ & 0.791 \\
\hline $\mathrm{mDC} 2 \mathrm{~s}, \times 10^{4} / \mathrm{ml}$ & $0.08 \pm 0.04$ & $0.08 \pm 0.05$ & 0.605 \\
\hline $\mathrm{mDCs}, \times 10^{4} / \mathrm{ml}$ & $1.71 \pm 0.64$ & $1.66 \pm 0.79$ & 0.825 \\
\hline $\mathrm{pDCs}, \times 10^{4} / \mathrm{ml}$ & $1.07 \pm 0.30$ & $1.22 \pm 0.41$ & 0.173 \\
\hline Mon1, \% monocytes & $82.84 \pm 6.17$ & $82.02 \pm 5.15$ & 0.754 \\
\hline Mon2, \% monocytes & $11.96 \pm 4.27$ & $9.43 \pm 5.15$ & 0.035 \\
\hline Mon3, \% monocytes & $4.93 \pm 3.22$ & $8.43 \pm 3.75$ & 0.001 \\
\hline Mon $1, \times 10^{5} / \mathrm{ml}$ & $3.25 \pm 0.96$ & $3.52 \pm 1.22$ & 0.470 \\
\hline Mon2, $\times 10^{4} / \mathrm{ml}$ & $5.17 \pm 1.92$ & $3.53 \pm 2.65$ & 0.045 \\
\hline Mon3, $\times 10^{4} / \mathrm{ml}$ & $2.23 \pm 1.44$ & $3.66 \pm 2.16$ & 0.059 \\
\hline
\end{tabular}

Values are mean \pm SD

Abbreviations as Table 1 and Table 2. P-values of risk factors with significance are presented as italic form 
with fibrous cap thickness $(r=-0.383, \mathrm{p}=0.014)$ and positively correlated with arc of lipid core $(r=0.413$, $p=0.001)$. However, the percentages and numbers of circulating DCs and Mon1 did not differ in UAP patients with and without calcified plaques (Additional file 9: Table S6).

Furthermore, according to the initiation and progression of atherosclerosis, the enrollments were divided into four groups as follows: control, non-TCFA, TCFA and STEMI groups. In this context, Fig. 1 shows a gradual increase in the proportion and absolute number of Mon2 subsets and a gradual decrease in the proportion of Mon3 subsets as the atherosclerosis worsen.

\section{Discussion}

In the present study, we investigated the association of circulating inflammatory cells with morphological characteristics of atherosclerotic plaque observed by coronary angiography and OCT. The results herein demonstrated that elevated CD14++CD16+ Mon2 subsets were associated with plaque vulnerability and rupture determined by angiography and OCT.

There were a growing number of researches regarding the relationships among circulating DCs, inflammation and their effects on coronary plaque, whereas conflicting results were reported. While Yilmaz et al. [13] and Kretzschmar et al. [20] observed markedly decreases in circulating mDCs, pDCs and total DCs in stable CAD and STEMI patients, Wen et al. [21] found a reduction in circulating $\mathrm{mDCs}$, but not $\mathrm{pDCs}$, in patients with unstable CAD. The disparate findings among published literatures may be explained as follow. Total DCs make up only approximate a 0.4 percentage of leukocytes in peripheral blood. It is thus conceivable that the absolute numbers of circulating DC subsets may fluctuate wildly because of changes in total leukocyte counts in different disease states and errors in operation. In our study, we observed that UAP and STEMI patients had a lower level of circulating $\mathrm{mDC} 2 \mathrm{~s}$ when compared with controls without coronary plaque. Human mDC2s share most features with murine $\mathrm{CD} 8 \alpha+\mathrm{DCs}$, while $\mathrm{mDC} 1 \mathrm{~s}$ represent human counterpart of murine CD $8 \alpha-$ DCs [22]. In response to viral infections and inflammatory stimuli, mDC1s activates $\mathrm{CD} 4+\mathrm{T}$ lymphocytes and possess the capacity to promote Treg differetiation [23]. Conversely, mDC2s prime CD8+ $\mathrm{T}$ lymphocytes [24]. The mechanisms of decreased circulating $\mathrm{mDC} 2 \mathrm{~s}$ in CAD are unclear; however, the possible theories have been postulated. In former studies, decreased circulating DCs in CAD were shown to be accompanied with a resident $D C$ increase in the inflamed plaques and infarct myocardium, inferring that circulating DC precursor recruitment to inflamed plaques was a part of the underlying disease process $[20,25]$. Additionally, the pathological study showed a high density of resident DCs with frequent $\mathrm{T}$ lymphocyte contacts in unstable plaques, suggesting that tissue-resident DCs, at least in

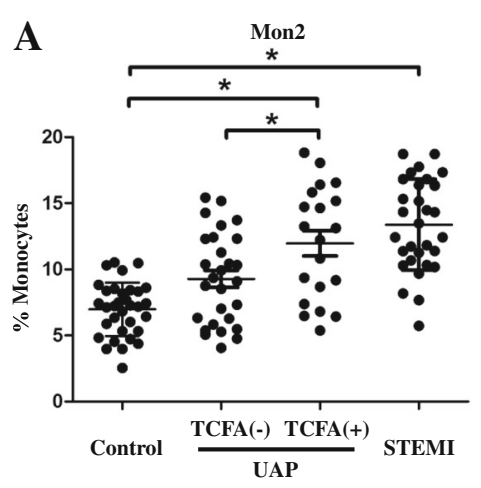

B
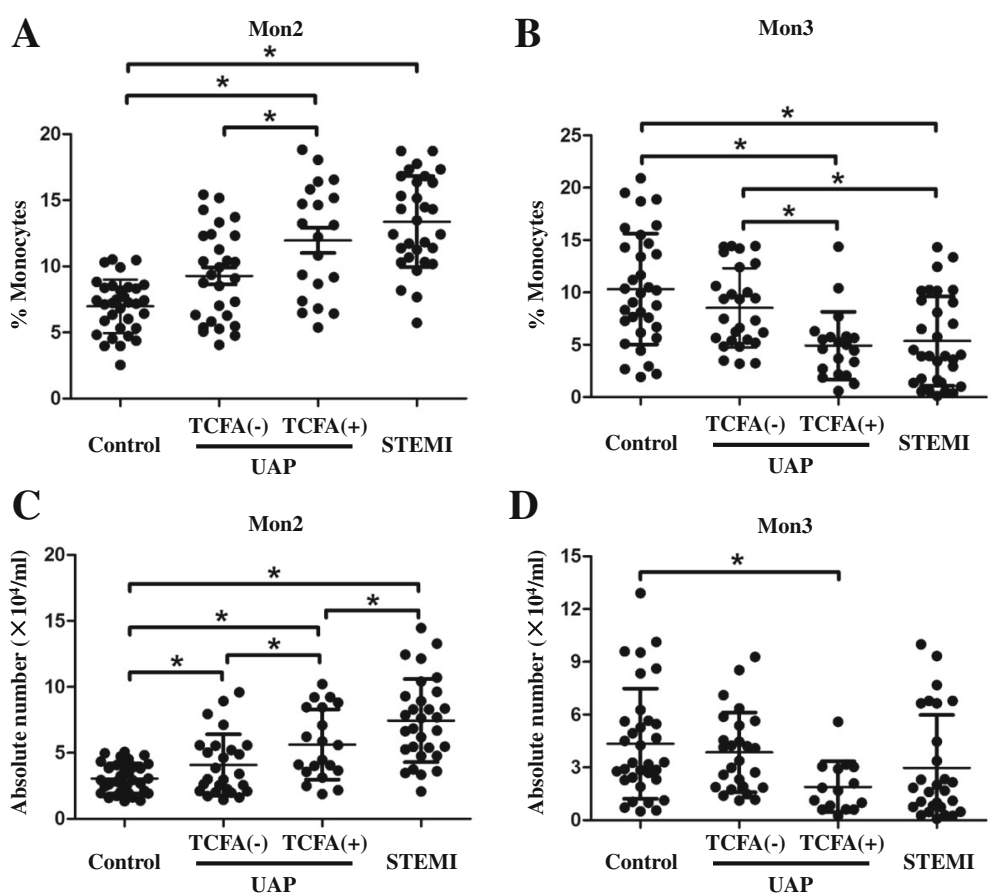

D

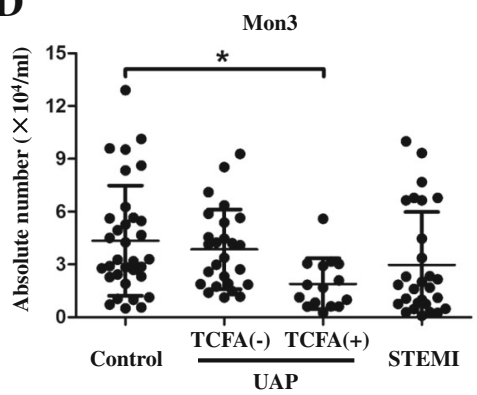

Fig. 1 Comparison of CD14++CD16+ Mon2 and CD14 + CD16++ Mon3 subsets at different stages of atherosclerosis. Comparison of the percentages of Mon2 (a) and Mon3 (b) subsets among four groups. Comparison of the absolute numbers of Mon2 (c) and Mon3 (d) among four groups. * $P<0.05$ 
part, facilitated local $\mathrm{T}$ lymphocyte activation and aggravated atherosclerotic development [26, 27]. Collectively, it is likely that decreased circulating $\mathrm{mDC} 2 \mathrm{~s}$ in CAD patients are caused by their recruitment into inflamed lesions and infarct myocardium. Subsequently, mature $\mathrm{mDC} 2 \mathrm{~s}$ in response to inflammatory stimuli within vulnerable plaques promote $\mathrm{CD} 8+\mathrm{T}$ lymphocyte activation and aggravate atherosclerotic development [27].

According to the severity of symptoms, some published studies grouped CAD patients into patients with stable angina pectoris (SAP) and with acute coronary syndrome (ACS). They reported that $\mathrm{mDCs}$ or $\mathrm{pDCs}$ were dramatically declined as CAD became more serious [13]. However, these subjects were not classified according to the plaque morphology in their coronary arteries. Although TCFA determined by OCT are found more prevalent in patients with ACS than in those with SAP, there are approximate $20 \%$ patients with SAP that have TCFA observed by OCT. [2] In agreement with the previous meta-analysis, the prevalence of TCFA is markedly higher in ACS group than that in SAP group [28]. TCFA harboring in patients with SAP seems to be neglected by clinical presentations but gradually evolve into plaque rupture [29]. Therefore, we applied OCT, which allows for the accurate assessment of plaque characteristics, to objectively identify the different stages of atherosclerosis. It should be noted that plaque rupture detected by OCT accounts for over $40 \%$ ACS, while the other ACS are caused by plaque erosion and calcified nodule [30]. As compared with plaque rupture, plaque erosion and calcified nodule are more prevalent in fibrous plaque than those in lipid plaque and TCFA [31]. Therefore, apart from vulnerable plaque characterized as TCFA, culprit plaque erosion and calcification pertain to fibrous plaque also contribute to the incidence of ACS. Additionally, TCFA alone is unable to correctly predict the adverse events in CAD patients. In contrast, TCFA combined with traditional risk factors is referred to be more feasible for evaluate the prognosis of CAD [28]. In patients undergoing coronary angiography, $\mathrm{mDC} 2 \mathrm{~s}$ were decreased in UAP and STEMI patients when compared with healthy controls, whereas the percentage and absolute number of $\mathrm{mDC} 2 \mathrm{~s}$ remained similar between UAP and STEMI patients. Moreover, as reported in the OCT subgroup, $\mathrm{mDC} 2 \mathrm{~s}$ were not significantly altered between patients with and without TCFA. Collectively, these results implied that decreased circulating $\mathrm{mDC} 2 \mathrm{~s}$ were associated with the presence of coronary plaque but not altered during plaque destabilization and rupture. Though CD11c + DCs were found to reside in vulnerable plaques in mice and humans, it was uncertain whether these resident DCs were derived from circulating common DC precursors or monocytes [25]. Moreover, the specific markers are needed to distinguish the different subsets of resident DCs in coronary plaques. [12]
Current studies unveil that monocyte subsets have different propensities to migrate the vascular wall and differentiate into particular subsets of DCs and macrophages located in plaques. [32, 33] This recognition prompted researchers to determine the association between distinct monocyte subsets and CAD. It is worth noting that some laboratories only referred to two monocyte subpopulations (CD14 + CD16- and CD14 + CD16+ monocytes). The consistent result of these studies was that the count of CD16 positive subsets was higher in patients with $\mathrm{CAD}$ and $\mathrm{MI}$ as compared with healthy controls.[34, 35] Rogacev et al. [9] found that the count of CD14++CD16+ Mon2 subsets was an independent predictor of adverse cardiovascular events. Tapp et al. [7] reported that circulating Mon2 subsets were prominently elevated in STEMI patients compared with patients with stable CAD and healthy volunteers. Our work extends the results of earlier studies on CAD patients diagnosed by coronary angiography. We showed that elevated CD14++CD16+ Mon2 subsets and reduced CD14 + CD16++ Mon3 subsets were associated with the presence and progression of coronary plaques determined by coronary angiography and OCT. In addition, we found that the proportion of circulating Mon3 subsets were positively correlated with fibrous cap thickness and negatively correlated with arc of lipid core, whereas none of monocyte subsets were significantly correlated with plaque volume. Considering that plaque composition, rather than plaque volume, plays an important role in the plaque disruption and subsequent thrombosis that leads to acute cardiovascular events [1], higher proportion and absolute number of Mon2 may provide important information to predict the presence of TCFA and the progression of atherosclerosis in coronary arteries.

Pathological studies have pushed forward the recognition of human monocyte heterogeneity and biological functions [5, 32]. Mechanistically, the intermediate Mon2 subsets expressing high levels of Tie-2 and CXCR4 possess pro-angiogenic properties [36, 37]. Recent studies uncovered that neovascularization of vasa vasorum within plaques facilitate macrophage infilitration and precipitate plaque vulnerability and rupture $[38,39]$. Another important mechanism is that circulating monocytes eventually differentiate into resident DCs/macrophages in atheroma and myocardium, and continue to function during the development of atherosclerosis and myocardial infarction [40]. In this regard, our results revealed that Mon1 and Mon2 were highly related to the serological markers of plaque rupture and myocardial infarction. Murine counterparts of human circulating monocytes could be delineated as Ly- $6 \mathrm{C}^{\text {hi }}$ and Ly- $6 C^{\text {lo }}$ monocytes. In murine experiments, Ly- $6 C^{\text {hi }}$ monocytes substantially increased in peripheral blood of 
Apoe-/- mice fed a high-fat diet and differentiated into pro-inflammatory M1-type macrophages, while Ly- $6 C^{\text {lo }}$ monocytes differentiated more readily into antiinflammatory M2-type macrophages [41]. Taken together, these phenomena suggest that both higher Mon2 counts may precipitate plaque destabilization and rupture.

\section{Study limitations}

There were some limitations associated with the present study. First, the study population was relatively small and the study design was cross-sectional in nature. Therefore, we were unable to distinguish whether or not the variation in circulating monocyte subsets is causative of atherosclerotic process. There is a need for prospective studies that investigate the predictive value of circulating DC and monocyte subsets for the development of coronary plaque. Additionally, currently, there was no standardization in the measurement of circulating DC and monocyte subsets.

\section{Conclusions}

Higher proportion and counts of Mon2 subsets are associated with atherosclerosis destabilization and rupture, which may be promising biomarkers for further clinic management.

\section{Additional files}

Additional file 1: Figure S1. Flow chart of the study. OCT = optical coherence tomography, STEMI = ST-segment elevation myocardial infarction, UAP = unstable angina pectoris. (TIFF $903 \mathrm{~kb}$ )

Additional file 2: Figure S2. Representative OCT images at culprit lesions. A. Fibrotic plaque. The thickness of fibrous cap was $130 \mu \mathrm{m}$. An arc delineates the lipid core. Arrows delineate the fibrous cap. B. Thin-cap fibroatheroma (TCFA). The thickness of fibrous cap was $60 \mu \mathrm{m}$. Arrows delineate the TCFA. C. Calcified plaque. (TIFF 8907 kb)

Additional file 3: Figure S3. Representative images showing the identification of circulating DC and monocyte subsets by flow cytometry. Upper panel, identification of $\mathrm{DC}$ subsets: $\mathrm{mDC} 1 \mathrm{~s}, \mathrm{mDC} 2 \mathrm{~s}$ and $\mathrm{pDC}$ were detected according to the markers. FSC/SSC dot plots were created to exclude debris and platelets. Gated on P1, CD14-/CD19-/SSC dot plots were generated. CD14+ monocytes, CD19+ B lymphocytes and CD14 -/CD19-/SSC+ granulocytes were excluded. Gated on P2, CD1C + region was drawn to identify mDC1s and CD141+ region was drawn to define mDC2s. CD303+ region was circled to identify pDCs. Lower panel, identification of monocyte subsets: Mon1, Mon2 and Mon3 were detected according to the markers. Gated on P3 by FSC/SSC, CD45 +/CD86 region was drawn to define total monocytes (P4 gate). Mon1, CD14++ CD16- monocytes; Mon2, CD14++CD16+ monocytes; Mon3, CD14+ CD16++ monocytes. FSC = Forward scatter, SSC = Side scatter. (TIFF 10999 kb)

Additional file 4: Table S1. Baseline characteristics of study population. (DOC $41 \mathrm{~kb}$ )

Additional file 5: Table S2. Total counts and proportions of DC and monocyte subsets in patients with and without smoking. (DOC $35 \mathrm{~kb}$ )

Additional file 6: Table S3. Correlation between glucose and triglyceride and circulating DC and monocyte subsets. (DOC 37 kb)
Additional file 7: Table S4. Correlation between inflammatory markers, myocardial necrotic markers and circulating DC and monocyte subsets. (DOC $45 \mathrm{~kb}$ )

Additional file 8: Table S5. Correlation between plaque characteristics and circulating DCs and monocytes. (DOC $40 \mathrm{~kb}$ )

Additional file 9: Table S6. Total counts and proportions of DC and monocyte subsets in patients with and without calcified plaque. (DOC 34 kb)

\section{Abbreviations}

CAD: Coronary artery disease; DC: Dendritic cell; Mon: monocyte; OCT: Optical coherence tomography; STEMI: ST-segment elevation myocardial infarction; TCFA: Thin-cap fibroatheroma; UAP: Unstable angina pectoris

\section{Acknowledgments}

We appreciate Fan Fan from Fudan University School of Medicine for her critical suggestions and comments on this manuscript.

\section{Funding}

This study was supported by Shanghai Municipal Commission of Health and Family Planning (No. 201440479) and National Natural Science Foundation of China (No. 81000113).

\section{Availability of data and materials}

All data generated or analyzed during this study are included in this published article and its supplementary information files. The raw datasets used and/or analyzed during the current study available from the corresponding author (Xiankai $\mathrm{Li}, \mathrm{MD}, \mathrm{PhD}$ ) on reasonable request.

\section{Authors' contributions}

JZ performed the flow cytometry and wrote the paper. YH designed the study and performed the statistical analysis. DX participated in patient recruitment and biochemical analysis. GZ participated in patient recruitment. SS participated in biochemical analysis. LC performed the flow cytometry. $M Z$ participated in patient recruitment and performed the statistical analysis. WC performed the coronary angiography and OCT analysis. YX performed the coronary angiography and OCT analysis. XL designed the study, performed the statistical analysis and wrote the paper. All authors read and approved the final manuscript.

Ethics approval and consent to participate

The study was approved by Ethics Committee of Shanghai Tenth People's Hospital and all individuals provided written informed concept before participation.

\section{Consent for publication}

Not applicable.

\section{Competing interests}

The authors declare that they have no competing interests.

\section{Publisher's Note}

Springer Nature remains neutral with regard to jurisdictional claims in published maps and institutional affiliations.

\section{Author details}

${ }^{1}$ Department of Cardiology, Shanghai Tenth People's Hospital, Tongji University School of Medicine, Shanghai, China. ${ }^{2}$ Department of Pathology, Shanghai East Hospital, Tongji University School of Medicine, Shanghai, China. ${ }^{3}$ Department of Cardiology, Shigatse People's Hospital, Shigatse, Tibet, China.

Received: 15 March 2017 Accepted: 10 October 2017 Published online: 18 October 2017

\section{References}

1. Finn AV, Nakano M, Narula J, Kolodgie FD, Virmani R. Concept of vulnerable/unstable plaque. Arterioscler Thromb Vasc Biol. 2010;30:1282-92. 
2. Jang IK, Tearney GJ, MacNeill B, Takano M, Moselewski F, Iftima N, Shishkov M, Houser S, Aretz HT, Halpern EF, Bouma BE. In vivo characterization of coronary atherosclerotic plaque by use of optical coherence tomography. Circulation. 2005:111:1551-5.

3. Fujii K, Hao H, Shibuya M, Imanaka T, Fukunaga M, Miki K, Tamaru H, Sawada H, Naito Y, Ohyanagi M, Hirota S, Masuyama T. Accuracy of OCT, grayscale IVUS, and their combination for the diagnosis of coronary TCFA: an ex vivo validation study. JACC Cardiovasc Imaging. 2015;8:451-60.

4. Mann DL. The emerging role of innate immunity in the heart and vascular system: for whom the cell tolls. Circ Res. 2011;108:1133-45.

5. Wong KL, Tai JJ, Wong WC, Han H, Sem X, Yeap WH, Kourilsky P, Wong SC. Gene expression profiling reveals the defining features of the classical, intermediate, and nonclassical human monocyte subsets. Blood. 2011;118: e16-31

6. Zawada AM, Rogacev KS, Rotter B, Winter P, Marell RR, Fliser D, Heine GH. SuperSAGE evidence for CD14++CD16+ monocytes as a third monocyte subset. Blood. 2011:118:e50-61.

7. Tapp LD, Shantsila E, Wrigley BJ, Pamukcu B, Lip GY. The CD14++CD16+ monocyte subset and monocyte-platelet interactions in patients with STelevation myocardial infarction. J Thromb Haemost. 2012;10:1231-41.

8. Liu Y, Imanishi T, Ikejima H, Tsujioka H, Ozaki Y, Kuroi A, Okochi K, Ishibashi K, Tanimoto T, Ino Y, Kitabata H, Akasaka T. Association between circulating monocyte subsets and in-stent restenosis after coronary stent implantation in patients with ST-elevation myocardial infarction. Circ J. 2010;74:2585-91.

9. Rogacev KS, Cremers B, Zawada AM, Seiler S, Binder N, Ege P, GrosseDunker G, Heisel I, Hornof F, Jeken J, Rebling NM, Ulrich C, Scheller B, Bohm M, Fliser D, Heine GH. CD14++CD16+ monocytes independently predict cardiovascular events: a cohort study of 951 patients referred for elective coronary angiography. J Am Coll Cardiol. 2012;60:1512-20.

10. Shantsila E, Tapp LD, Wrigley BJ, Pamukcu B, Apostolakis S, Montoro-Garcia S, Lip GY. Monocyte subsets in coronary artery disease and their associations with markers of inflammation and fibrinolysis. Atherosclerosis. 2014;234:4-10.

11. Mildner A, Jung S. Development and function of dendritic cell subsets. Immunity. 2014;40:642-56.

12. Zernecke A. Dendritic cells in atherosclerosis: evidence in mice and humans. Arterioscler Thromb Vasc Biol. 2015;35:763-70.

13. Yilmaz A, Schaller T, Cicha I, Altendorf R, Stumpf C, Klinghammer L, Ludwig J, Daniel WG, Garlichs CD. Predictive value of the decrease in circulating dendritic cell precursors in stable coronary artery disease. Clin Sci (Lond). 2009;116:353-63.

14. Fukunaga $T$, Soejima $H$, Irie $A$, Fukushima $R$, Oe $Y$, Kawano $H$, Sumida $H$, Kaikita K, Sugiyama S, Nishimura Y, Ogawa H. High ratio of myeloid dendritic cells to plasmacytoid dendritic cells in blood of patients with acute coronary syndrome. Circ J. 2009;73:1914-9.

15. Braunwald E. Unstable angina. A classification. Circulation. 1989:80:410-4

16. Thygesen K, Alpert JS, Jaffe AS, Simoons ML, Chaitman BR, White HD, Katus HA, Lindahl B, Morrow DA, Clemmensen PM, Johanson P, Hod H, Underwood R, Bax JJ, Bonow RO, Pinto F, Gibbons RJ, Fox KA, Atar D, Newby LK, Galvani M, Hamm CW, Uretsky BF, Steg PG, Wijns W, Bassand JP, Menasche P, Ravkilde J, Ohman EM, Antman EM, Wallentin LC, Armstrong PW, Januzzi JL, Nieminen MS, Gheorghiade M, Filippatos G, Luepker RV, Fortmann SP, Rosamond WD, Levy D, Wood D, Smith SC, Hu D, LopezSendon JL, Robertson RM, Weaver D, Tendera M, Bove AA, Parkhomenko AN, Vasilieva EJ, Mendis S. Third universal definition of myocardial infarction. Circulation. 2012;126:2020-35.

17. Prati F, Regar E, Mintz GS, Arbustini E, Di Mario C, Jang IK, Akasaka T, Costa M, Guagliumi G, Grube E, Ozaki Y, Pinto F, Serruys PW. Expert review document on methodology, terminology, and clinical applications of optical coherence tomography: physical principles, methodology of image acquisition, and clinical application for assessment of coronary arteries and atherosclerosis. Eur Heart J. 2010;31:401-15.

18. Tearney GJ, Regar E, Akasaka T, Adriaenssens T, Barlis P, Bezerra HG, Bouma B, Bruining N, Cho JM, Chowdhary S, Costa MA, de Silva R, Dijkstra J, Di Mario C, Dudek D, Falk E, Feldman MD, Fitzgerald P, Garcia-Garcia HM, Gonzalo N, Granada JF, Guagliumi G, Holm NR, Honda Y, Ikeno F, Kawasaki M, Kochman J, Koltowski L, Kubo T, Kume T, Kyono H, Lam CC, Lamouche G, Lee DP, Leon MB, Maehara A, Manfrini O, Mintz GS, Mizuno K, Morel MA, Nadkarni S, Okura H, Otake H, Pietrasik A, Prati F, Raber L, Radu MD, Rieber J, Riga M, Rollins A, Rosenberg M, Sirbu V, Serruys PW, Shimada K, Shinke T, Shite J, Siegel E, Sonoda S, Suter M, Takarada S, Tanaka A, Terashima M,
Thim T, Uemura S, Ughi GJ, van Beusekom HM, van der Steen AF, van Es GA, van Soest G, Virmani R, Waxman S, Weissman NJ, Weisz G. Consensus standards for acquisition, measurement, and reporting of intravascular optical coherence tomography studies: a report from the international working Group for Intravascular Optical Coherence Tomography Standardization and Validation. J Am Coll Cardiol. 2012:59:1058-72.

19. Tapp LD, Shantsila E, Wrigley BJ, Montoro-Garcia S, Lip GY. TLR4 expression on monocyte subsets in myocardial infarction. J Intern Med. 2013:273:294-305.

20. Kretzschmar D, Betge S, Windisch A, Pistulli R, Rohm I, Fritzenwanger M, Jung C, Schubert K, Theis B, Petersen I, Drobnik S, Mall G, Figulla HR, Yilmaz A. Recruitment of circulating dendritic cell precursors into the infarcted myocardium and pro-inflammatory response in acute myocardial infarction. Clin Sci (Lond). 2012;123:387-98.

21. Wen J, Wen Y, Zhiliang L, Lingling C, Longxing C, Ming W, Qiang F. A decrease in the percentage of circulating $\mathrm{mDC}$ precursors in patients with coronary heart disease: a relation to the severity and extent of coronary artery lesions? Heart Vessel. 2013;28:135-42.

22. Geginat J, Nizzoli G, Paroni M, Maglie S, Larghi P, Pascolo S, Abrignani S. Immunity to pathogens taught by specialized human dendritic cell subsets. Front Immunol. 2015:6:527.

23. Layseca-Espinosa E, Korniotis S, Montandon R, Gras C, Bouillie M, GonzalezAmaro R, Dy M, Zavala F. CCL22-producing CD8alpha- myeloid dendritic cells mediate regulatory $T$ cell recruitment in response to G-CSF treatment. J Immunol. 2013;191:2266-72.

24. Kang SJ. The bloodline of CD8alpha(+) dendritic cells. Mol Cells. 2012;34 219-29.

25. Yilmaz A, Weber J, Cicha I, Stumpf C, Klein M, Raithel D, Daniel WG, Garlichs CD. Decrease in circulating myeloid dendritic cell precursors in coronary artery disease. J Am Coll Cardiol. 2006:48:70-80.

26. Yilmaz A, Lochno M, Traeg F, Cicha I, Reiss C, Stumpf C, Raaz D, Anger T, Amann K, Probst T, Ludwig J, Daniel WG, Garlichs CD. Emergence of dendritic cells in rupture-prone regions of vulnerable carotid plaques. Atherosclerosis. 2004;176:101-10.

27. Cochain C, Koch M, Chaudhari SM, Busch M, Pelisek J, Boon L, Zernecke A. CD8+ T cells regulate Monopoiesis and circulating Ly6C-high monocyte levels in atherosclerosis in mice. Circ Res. 2015;117:244-53.

28. lannaccone M, Quadri G, Taha S, D'Ascenzo F, Montefusco A, Omede P, Jang IK, Niccoli G, Souteyrand G, Yundai C, Toutouzas K, Benedetto S, Barbero U, Annone U, Lonni E, Imori Y, Biondi-Zoccai G, Templin C, Moretti C, Luscher TF, Gaita F. Prevalence and predictors of culprit plaque rupture at OCT in patients with coronary artery disease: a meta-analysis. Eur Heart J Cardiovasc Imaging. 2016;17:1128-37.

29. Ahmadi A, Leipsic J, Blankstein R, Taylor C, Hecht H, Stone GW, Narula J. Do plaques rapidly progress prior to myocardial infarction? The interplay between plaque vulnerability and progression. Circ Res. 2015;117:99-104.

30. Jia H, Abtahian F, Aguirre AD, Lee S, Chia S, Lowe H, Kato K, Yonetsu T, Vergallo R, Hu S, Tian J, Lee H, Park SJ, Jang YS, Raffel OC, Mizuno K, Uemura S, Itoh T, Kakuta T, Choi SY, Dauerman HL, Prasad A, Toma C, McNulty I, Zhang S, Yu B, Fuster V, Narula J, Virmani R, Jang IK. In vivo diagnosis of plaque erosion and calcified nodule in patients with acute coronary syndrome by intravascular optical coherence tomography. J Am Coll Cardiol. 2013;62:1748-58.

31. Higuma T, Soeda T, Abe N, Yamada M, Yokoyama H, Shibutani S, Vergallo R, Minami Y, Ong DS, Lee H, Okumura K, Jang IK. A combined optical coherence tomography and intravascular ultrasound study on plaque rupture, plaque erosion, and calcified nodule in patients with ST-segment elevation myocardial infarction: incidence, morphologic characteristics, and outcomes after percutaneous coronary intervention. JACC Cardiovasc Interv. 2015;8:1166-76.

32. Woollard KJ, Geissmann F. Monocytes in atherosclerosis: subsets and functions. Nat Rev Cardiol. 2010;7:77-86.

33. Auffray C, Sieweke MH, Geissmann F. Blood monocytes: development, heterogeneity, and relationship with dendritic cells. Annu Rev Immunol. 2009;27:669-92

34. Ozaki $Y$, Imanishi T, Taruya A, Aoki H, Masuno T, Shiono Y, Komukai K Tanimoto T, Kitabata H, Akasaka T. Circulating CD14+CD16+ monocyte subsets as biomarkers of the severity of coronary artery disease in patients with stable angina pectoris. Circ J. 2012;76:2412-8.

35. Kashiwagi M, Imanishi T, Ozaki Y, Satogami K, Masuno T, Wada T, Nakatani $Y$ Ishibashi K, Komukai K, Tanimoto T, Ino Y, Kitabata H, Akasaka T. Differential 
expression of toll-like receptor 4 and human monocyte subsets in acute myocardial infarction. Atherosclerosis. 2012;221:249-53.

36. Matsubara T, Kanto T, Kuroda S, Yoshio S, Higashitani K, Kakita N, Miyazaki M, Sakakibara M, Hiramatsu N, Kasahara A, Tomimaru Y, Tomokuni A, Nagano H, Hayashi N, Takehara T. TIE2-expressing monocytes as a diagnostic marker for hepatocellular carcinoma correlates with angiogenesis. Hepatology. 2013;57:1416-25.

37. Ghattas A, Griffiths HR, Devitt A, Lip GY, Shantsila E. Monocytes in coronary artery disease and atherosclerosis: where are we now? J Am Coll Cardiol. 2013;62:1541-51.

38. Celletti FL, Waugh JM, Amabile PG, Brendolan A, Hilfiker PR, Dake MD. Vascular endothelial growth factor enhances atherosclerotic plaque progression. Nat Med. 2001;7:425-9.

39. Jaipersad AS, Lip GY, Silverman S, Shantsila E. The role of monocytes in angiogenesis and atherosclerosis. J Am Coll Cardiol. 2014;63:1-11.

40. Ley K, Miller YI, Hedrick CC. Monocyte and macrophage dynamics during atherogenesis. Arterioscler Thromb Vasc Biol. 2011;31:1506-16.

41. Swirski FK, Libby P, Aikawa E, Alcaide P, Luscinskas FW, Weissleder R, Pittet MJ. Ly-6Chi monocytes dominate hypercholesterolemia-associated monocytosis and give rise to macrophages in atheromata. J Clin Invest. 2007;117:195-205.

\section{Submit your next manuscript to BioMed Central} and we will help you at every step:

- We accept pre-submission inquiries

- Our selector tool helps you to find the most relevant journal

- We provide round the clock customer support

- Convenient online submission

- Thorough peer review

- Inclusion in PubMed and all major indexing services

- Maximum visibility for your research

Submit your manuscript at www.biomedcentral.com/submit 